\title{
Disneylandización de la naturaleza y políticas verdes
}

\author{
José M. Echavarren*
}

Cuando se acerca el siglo XXI hay un renovado interés por los libros de ecología, naturaleza y crítica de la sociedad. La política social sobre esos temas es un área de considerable debate. La distribución de recursos sociales y sanitarios no se entiende sin una visión más general del entorno en el que sociedad y naturaleza interaccionan. Aquí se desarrolla una revisión sociológica de tres posiciones relevantes sobre el tema. Ciertos supuestos sociales parecen irreales por lo banal de su contenido. Cualquier actor social que presuntamente las comparte, después de un breve análisis lógico, las rechazaría por su aparente simplicidad social: "¿Disneylandización de la naturaleza? ¿Naturaleza como no-lugar?. La característica más importante del mundo cotidiano es la del aser dado por supuesto" (taken for granted). Como señala SchuTz (1899-1959), se trata de ideas comúnmente aceptadas dentro del mundo de la vida diaria que no son cuestionadas ni analizadas críticamente, que son simplemente dadas por supuesto. Estas ideas se respaldan en mitos sociales ampliamente extendidos, como que alas mujeres llevan a lo peor. 0 "los pobres son unos vagos" ".

La importancia de las concepciones irreales de la realidad es tratada extensamente por corrientes sociológicas como el interaccionismo simbólico, que supone que los seres humanos tra$\tan$ a las cosas en función del significado que tienen para ellas. Pero siguiendo el Principio de Thomas, esas concepciones irreales tienen sus efectos en la realidad. Para Peter BERGER y Thomas LUCKMAN, esas ideas y mitos sociales, gestados y desarrollados en la interacción social, llegan a devenir en realidad objetiva para los mismos actores por un principio de objetiva- ción. Las ideas son externas a los sujetos, y se enfrentan a ellos como realidades objetivas. Este proceso de reificación, dentro de la terminología marxiana, es internalizado en los sujetos por una socialización que hace incluso más externos y naturales esos mitos sociales. Unas nociones irreales creadas por las personas en el marco de ciertos mitos sociales, se vuelven reales para los mismos actores, afectando a sus actos, esto es, a la realidad misma. Se trata del Principio de Thomas (tan querido por los sociólogos) por el cual si algo se interpreta como real tiene consecuencias reales.

La población conserva a menudo dos actitudes contrarias entre sí, aparentemente sin problemas ni escrúpulos morales. Consumo sin freno y deforestación van de la mano con ecologismo y protección del medio ambiente. Las dos ideas no se ponen en relación mutua (a pesar de tenerla) pues podrían generar remordimientos. Suelen ser confinadas en apartamentos estancos desde donde se las llama cuando la situación social así lo exige. Juan M. IRANzo ${ }^{2}$ señala con agudeza que el ecologismo tiene menos dimensión revolucionaria de lo que parecería a primera vista: $\mathrm{A} \mathrm{El}$ ecologismo puede sancionar pasivamente la estructura de poder vigente mientras no cuestione la iniciativa privada [...] ni la poliarquía vigente [...] y sólo condene la desigualdad extrema [...] mientras critique la distribución de las rentas y no de la propiedad y acepte la necesidad de, al menos, cierto crecimiento económico [...] una religión civil que logra movilizar más la autosatisfacción con un modo de vida sostenible que la equidad y la solidaridad ${ }^{3}$. "Hay estrategias para eludir la responsabilidad ecológica y asumir medidas realistas. El 
pesimismo estructural es un método mas. „Para qué hacer algo si el desastre ecológico es inevitable?. Este pesimismo negativo ${ }^{4}$ que no aporta soluciones, ni actitud activa, sino simplemente sanciona la fuerza de la inercia, se desdobla en dos tipos de discursos: el discurso exculpatorio ( los coches contaminan el aire", .se está acabando con el Amazonas") o el discurso victimista ("nos envenenan - ellos $\rightarrow$, aya no se puede respirar - por su culpa $\rightarrow$ ). Pero hay un factor más, hondamente arraigado en la sociedad urbana avanzada, que justifica y posibilita a menudo la destrucción del medio ambiente y las especies animales que en él habitan. La construcción social de una naturaleza ideal que convierte en una naturaleza falsa, o una naturaleza incompleta la verdadera naturaleza, sancionando su destrucción.

La última década del siglo XX está asistiendo a un proceso excepcional: la construcción social de una naturaleza desvinculada de la realidad, que tiende a ocupar el lugar de su referente. Esta naturaleza idealizada, configurada por y en la comunidad social, e irradiada por los medios de comunicación, toma lugar en el contexto de la cultura urbana de las sociedades. Las poblaciones que conviven y tienen tradición de convivir con la naturaleza, dificilmente confunden ésta con una naturaleza fantástica. Sus características pueden analizarse desde varias perspectivas. Se trata de una naturaleza adisneylandizada donde la violencia es condenada, convirtiéndose en una idealización donde la violencia es desterrada. Las relaciones entre animales se presentan como armónicas, adjudicando una categoría moral a los animales que transmite felicidad y tranquilidad de ánimo en su conjunto.

Los animales carnivoros son así olvidados, o simplemente se elimina su carácter carnivoro y agresivo. Leones y tigres pasan a ser gatitos grandes, y los osos (que se identifican con sus homónimos de peluche, abrazables) sólo comen pescado y raíces. También son dejados de lado otros animales que no resultan estéticos (babosas, ratas) o con los que la conexión empática no es tan fácil (buitres, hienas, serpientes). Se produce una estratificación de la jerarquía animal donde el elefante y sobre todo el león es el rey. Es una naturaleza agradable para el ser bumano, ya que, al haber sido creada por éste, es forzosamente de su agrado. Debe ser también segura. No hay animales que puedan o deseen hacer daño. Se tiene en cuenta así el carácter moral de sus habitantes, capaces de elegir y considerar la bon$\mathrm{dad} / \mathrm{maldad}$ de sus acciones, y en donde atacar a un ser humano es considerado como punible. Tampoco existe allí la malaria ni enfermedad alguna.

La difusión de esta naturaleza idealizada se debe a su multiformidad, ya que no existe un consenso generalizado de cómo es o debería ser. Sólo unas líneas generales, como las ya apuntadas arriba, son las que configuran la idea base. El resto se debe a cada persona, que decora e interpreta esa naturaleza idealizada a su propia manera. En esta naturaleza ideal se en- cuentran formas diferentes con un mismo fondo: playas con cocoteros, selvas amazónicas, o prados inmensos salpicados de árboles, aunque difícilmente se encuentran desiertos; paisajes volcánicos o zonas árticas (a pesar de ser todos diferentes facetas de la naturaleza). Sí se puede encontrar a Bambi, osos panda y koalas, pero más que probablemente no al lobo, cocodrilos gigantes, ni tiburones.

Otra característica de esa naturaleza disneylandizada es la de ser un no-lugar ${ }^{5}$. Se caracteriza por ser ahistórico, no identificatorio y arrelacional. Augé utiliza el concepto para referirse sobre todo a lugares de paso físicos, ya existentes, pero puede ser también usado en esta línea. La naturaleza ideal es ahistórica al no haber existido nunca, arrelacional y no identificatoria, a no ser que sea autoidentificatoria. Esta naturaleza disneylandizada funciona como un no-lugar al que acude la gente en ocasiones diversas. Cuando se participa en un sorteo en el que el premio es un viaje al Caribe o un safari, se viaja por un momento a ese no-lugar, al que a pesar de no haber estado nunca se conoce bastante bien. Se recurre a la naturaleza, porque su importancia en la sociedad finisecular aumenta diariamente, desde los ámbitos sociales a los económicos. Es una imagen nítida, aunque para los/las científicos sociales y políticos sea difícil de definir y suela bastar con sentirse.

La idealización de la naturaleza como no-lugar enmascara ciertos aspectos de la realidad social, aunque otros son disfrazados de un modo más activo por las personas con el fin de mantenerse en coherencia con respecto a esa imagen idealizada. Una de las falsedades usuales es la negación del carácter depredador del ser humano. El carnívoro salvaje es tachado como moralmente reprobable, porque al cazar animales que son sujetos dotados de juicio ético, no estaría simplemente cazando, sino asesinando. Pero ¿cómo negar la naturaleza depredadora del ser humano? "Depredación es el consumo de un organismo (la presa) por parte de otro organismo (el depredador) estando la presa viva cuando el depredador la ataca por primera vez ${ }^{6}$. ¿Quién come actualmente animales vivos? Los caracoles y las ostras son cocidos vivos, pero generalmente se suele pasar por alto este hecho (para alivio de conciencias quizá demasiado sensibles). En todo caso es difícil que se le otorgue un carácter moral a esos animales, distantes del ser humano en la escala evolutiva. Se realiza pues un enmascaramiento de las relaciones de producción de nuestros alimentos, donde la violencia (de la caza/pesca o del matadero) es excluida.

La mayoría de los animales que se comen son además cuidadosamente mutilados, de tal forma que apenas evocan su forma original ${ }^{7}$. Es simplemente comida, no un pollo ni un pato. Para el dado por supuesto del día a día, es comida producida en una fábrica, de la misma forma que se producen coches o cafeteras. La no-lugarización de la naturaleza, al separar las consecuencias ecológicas de la producción, incrementa lógicamente 
los beneficios existentes. Hay otra forma de enmascaramiento: No se suele saber, ni tampoco preguntar, a dónde van los desechos que producen los seres humanos en la sociedad contemporánea. El consumo produce muchos desechos, pero ser consciente de ello resultaría enojoso, y generaría un sentimiento de culpabilidad al consumir, o peor aún, se consumiría menos. Se da por supuesto que los desechos desaparecen en cuanto no los vemos. En la naturaleza como no-lugar nunca se ven montañas de basura ni estercoleros. Así pues, ¿para qué preocuparse?

La naturaleza emerge como valor de cambio en una sociedad donde lo ecológico adquiere importancia en todo tipo de situaciones. A nivel individual ser sano y natural, aunque no se sepa en qué consiste, es un valor en la interacción social. Puede conllevar un aumento de prestigio en un determinado círculo de actores sociales. A un nivel más macro, incluso los partidos políticos se ven obligados a adoptar políticas verdes, las fábricas producen coches ecológicos (que "contaminan ecológicamente), y algunas empresas multinacionales subvencionan reservas naturales en países tercermundistas. La naturaleza adopta así un valor de consumo, incluido en el deporte, vacaciones naturales y segundas residencias. También se produce un valor de consumo individual, con una mitificación de la salud y del cuerpo, el consumo de productos light y ecológicos. La naturaleza es mercantilizada (commodified) y se añade como valor a un sinfín de productos, cosa que aparece patente en los anuncios publicitarios en televisión y otros medios. Aparecen dentifricos que ofrecen al usuario/a frescor salvaje, colonias que sugieren viajes en canoa al trabajo desde las montañas, y, sobre todo, coches que exploran territorios ignotos. Casi no hay un anuncio de coche que no pasee al conductor por la selva o el bosque, cuando realmente el $90 \%$ del tiempo ese coche va a conducirse por ciudad.

Estas ideas críticas pueden verse también en el mundo de la imagen, sobre todo en televisión y cine ${ }^{8}$. El objeto del análisis de Babe, el cerdito valiente radica en comprobar si es posible encontrar las características sobre la naturaleza idealizada en una película moderna y de cierto éxito de taquilla. Se puede analizar la forma en que esas ideas son mercantilizadas a través del cine. La sinopsis es la siguiente: Babe es un cerdito que se vende en una feria a Mr. Hogget, el dueño de una granja de Gales. Babe es adoptado por la perra ovejera de Mr. Hogget, Fly, y es iniciado en el arte del pastoreo aun a pesar del perro pastor Rex, compañero de Fly, apegado a las tradiciones perrunas. Mr. Hogget se percata de la habilidad del cerdito Babe con las ovejas (que le obedecen porque las trata con suavidad y amabilidad) y lo lleva a un concurso de perros ovejeros, donde el cerdito protagonista consigue la máxima puntuación. De la película merecen destacarse varias cosas. No es una película de dibujos animados, sino de imagen real, donde los animales son de verdad, excepto en determinadas escenas donde se sustitu- yen por marionetas. La idea de naturaleza que transmite es mucho más convincente y por lo tanto peligrosa. Al estilo del Animal Farm de George Orwell, todos los animales tienen nombre, un rasgo que les otorga una categoría moral especial ${ }^{9}$. Aparecen así humanizados en su caracterización. A Babe lo adoptan como si fuese un hijo (llama a Fly amamás) e incluso llora en una escena cuando le comentan que su verdadera madre fue devorada por los humanos. En la comida de Acción de Gracias los humanos se comen a una pata, Fernanda, y cuando la trinchan la escena adopta tintes macabros. Ser camívoro es considerado como un atentado moral, porque entraña violencia en un mundo que se supone dócil y armónico. La pocilga que Babe y sus hermanitos comparten con su madre al inicio de la película está extrañamente limpia, sobre todo tratándose de cerdos. Pero la suciedad y la basura no tienen cabida en una naturaleza disneylandizada.

El tema predominante en la película es la violencia. Los pemos muerden a las ovejas, las maltratan para que hagan lo que quiere el amo. Un consejo de Fly a Babe es que es conveniente que las ovejas "sepan quién es el que manda" y ano pedimos: simplemente les decimos lo que tienen que hacer. Los perros consideran estúpidas a las ovejas porque tardan mucho en obedecer órdenes simples. Por su parte, las ovejas los consideran a ellos ignorantes, porque no saben cómo tratarlas. Babe pide a las ovejas con amabilidad y ellas le obedecen más rápidamente que a los perros. La violencia se considera como inútil, y debe desaparecer. Las jerarquías son contraproducentes. Las relaciones de consenso, de armonía, son las que deben imperar en la naturaleza. En esa naturaleza del no-lugar no hay violencia y las relaciones entre animales son armónicas.

La naturaleza como no-lugar es una construcción social. Cabría preguntarse por qué se configura precisamente de ese modo. Si esa naturaleza idealizada no tiene un referente real, no queda claro de dónde y por qué surge. Una explicación a tal suceso puede realizarse siguiendo una interpretación de la teoría de FREUD (1856-1939) sobre el enamoramiento, y que aquí se extrapola del individuo a la masa ${ }^{10}$. La teoría del enamoramiento de FrEUD apela al narcisismo de las personas y de la masa en su conjunto. El objeto amado " (que aquí es la naturaleza disneylandizada) sirve para sustituir un ideal del yo no alcanzado. Es decir, la naturaleza es venerada por las mismas perfecciones que la persona desea para sí misma. La población proyecta su propio ideal del ego, el conjunto de las aspiraciones narcisistas, que por tanto es necesariamente amado. Ia masa, al compartir una serie de características comunes, proyecta también a esa naturaleza una serie de rasgos ideales (como libertad, belleza, espontaneidad, tranquilidad) que se posicionan como valores importantes en la sociedad urbana de fin de siglo. Posteriormente, cada persona realiza su propia interpretación del mito al proyectar imágenes narcisistas más concretas. Así se 
obtiene ese paisaje natural ideal tan compartido por lo vago de su formulación, pero diferente en sus distintas personificaciones. Se producen conductas extremas, como son las incluidas en el concepto del ayo devorado. El yo del sujeto es absorbido, devorado, por la imagen del objeto amado, haciéndose cada vez menos exigente, aumentando su carácter dependiente y siendo igual finalmente la medida en torno a la cual se juzga y compara lo demás. El objeto (amado) se apodera de todo el amor que siente el sujeto por sí mismo, quedando sustraído a la crítica, y elevando sus cualidades a los más altos valores. Ese papel es ocupado por algunos ecologistas radicales, que llevan su amor a la naturaleza (formado en este caso por su ideal del yo, y sobre todo por las características generales del ideal del yo de la masa) a un nivel tal que los anulan como seres individuales. Cuando el sujeto introyecta las cualidades del objeto amado para su propio enriquecimiento personal, pero en ese amor exagerado el actor social se da por entero, produciéndose el proceso de devoramiento de su propio ego. Se puede dar una vuelta de tuerca más, y así el ecologismo se convierte en un catalizador de esos sentimientos y actitudes, tomando la forma de una religión civil ${ }^{12}$. El amor a la naturaleza queda así casi sacralizado. Se observan una serie de rituales de culto que los/as actores sociales cumplen con mas o menos intensidad en función de su adhesión a la fe ecologista, como son pagar cuotas a alguna organización ecologista, coleccionar documentales sobre la naturaleza, subir al monte los fines de semana, tener macetas en el balcón, y en particular orientar su consumo a productos "naturales" ${ }^{13}$. Ese falso ecologismo, creado únicamente para aglutinar y dar forma a todo un conjunto de sentimientos hacia la naturaleza disneylandizada, se suele articular en torno a premisas que tienen menos validez de lo que cabría suponer ${ }^{14}$. Pero la utilidad del ecologismo no se mide por su funcionalidad en la protección de la naturaleza, sino por su capacidad de representar las creencias de sus "feligreses. A pesar de sus pretensiones globalizadoras, el ecologismo parece ser una religión circunscrita al ámbito urbano, del mismo modo que la nolugarización de la naturaleza es también un fenómeno urbano. Se desarrolla a través de una desvinculación con el medio natural que provoca su desconocimiento, convertido a la persona en vulnerable a posibles idealizaciones de la naturaleza, y a la visión light de la naturaleza. En España, ese fenómeno se produce con mas fuerza en la juventud, por ser la primera generación realmente urbana. Se puede entender este amor por la naturaleza en su contexto, como aclara un adolescente barcelonés: aEl campo me aburre. El campo me gusta para ir, estar un fin de semana, algún verano, ir a respirar aire puro y recargar baterías. Pero lo que realmente me gusta son las ciudades. Una gran ciudad no me molestaría si fuera un poco mas verde, con jardines. Se deberían naturalizar un poco las grandes ciudades" ${ }^{15}$. En La sociedad transversal, los sociólogos Jesús M. DE MIGUEL, Emilio J. CASTILLA y Jordi CAïs, observan en esta generación una crítica ni- hilista a las cosas, que enlaza con el pesimismo estructural que lejos de aportar soluciones se deja arrastrar por la fuerza de la inercia. El hedonismo en la sociedad actual es otra característica que contribuye a la huida hacia una naturaleza imaginaria, más allá del dolor, del sufrimiento, y la violencia, que quedan convertidas en tabú. Hoy en día las personas no mueren, sino que "desaparecen. La cultura de la salud es casi obsesiva, como si por no fumar, ni beber, ni comer grasas, una persona fuera a ser inmortal. Son sólo ejemplos característicos de la actual tendencia a ocultar ciertos aspectos de la realidad que no resultan agradables bajo una máscara decorada con motivos naturales pero de manufactura humana.

Del análisis de la relación sociedad-naturaleza, y su impacto en las políticas verdes, se desprende que esta nueva naturaleza es de indole urbana. Pero es un error circunscribirla a lo que se entiende normalmente como "ciudad", siendo más correcto hablar de telépolis ${ }^{16}$. La telépolis no se asienta sobre un espacio bidimensional, que podría ser reflejado en un plano, no tiene fronteras precisas. Tampoco tiene perspectiva visual ni geográfica. Es multidimensional. Para orientarse o tratar de abarcarla no basta con consultar mapas, sino que son necesarias bases de datos múltiples, cada una de las cuales puede ofrecer sólo una dimensión particular de la estructura global. Se trata de una ciudad que se escapa a las demarcaciones territoriales y que se extiende mas allá de lo que resultaría previsible en un principio. Esta postciudad, (¿postindustrial?, ¿postfordista?) del siglo XXI, se extiende progresivamente, como una mancha de aceite, transformando territorios lejanos a ella inicialmente. Cada vez cubre más territorio.

Al fin de este siglo XX se observa un crecimiento demográfico y urbano en todo el planeta Tierra. Se prevé que para el año 2000 el 50\% de la población europea vivirá en ciudades, donde la llamada "Dorsal Europea" agrupa ya a las ciudades más importantes de Alemania, Reino Unido, Francia y norte de Italia, que suman el $47 \%$ de la población europea. Paralelamente se produce una urbanización del campo que gira en torno a cuatro fenómenos ${ }^{17}$ : (a) Un número cada vez más importante de personas eligen ir a vivir al campo, pero sin romper sus vínculos laborales y sociales con la ciudad. (b) En la misma línea, se observa el fenómeno del "obrero-campesino". El campesino/a que ya no puede asegurarse un nivel de vida satisfactorio únicamente con las ganancias del campo, y trabaja también en la ciudad. (c) Se produce un movimiento constante de las ciudades a los espacios rurales en busca de ocio y espacios de esparcimiento. (d) También se produce un aumento del fenómeno de la segunda residencia. La consecuencia es una colonización cultural: "La sociedad rural se ha abierto al exterior y ha intercambiado información y prácticas sociales con el entorno que la rodea. Los pueblos han perdido su aislamiento tradicional y viven los problemas del país como cualquier ciudadano: se viste 
como se viste en la ciudad, se consumen los productos del mercado, y en los bares de los pueblos se habla de política y se comentan los temas de corrupción como cualquier otro centro de reunión. ${ }^{18}$. Otro factor importante es la progresiva terciarización de las actividades económicas que modifican los patrones sociales hacia el modo de vida urbano, con un contacto cada vez más continuado y progresivo con los aurbanitas" y una mayor dependencia económica de la metrópolis. Como recomienda Benjamín GARCíA SANZ, conviene matizar la absorción rural por lo urbano, al observarse ciertos sintomas de una resistencia cultural frente a la ciudad $^{19}$. Aunque el cambio no es total, se produce una transformación sustancial de las formas de vida tradicional en favor de un tímido acercamiento a lo urbano. El varón/mujer rural, como persona que trabaja la tierra, no cambia el paisaje, y no está dentro de la historia, está desapareciendo.

La ciudad gana terreno dja a día, pero esta expansión se reali$z a$ en detrimento de los espacios naturales. La naturaleza como no-lugar y el ecologismo como religión civil, tienen un papel activo en todo ello. La vida de la actriz social se estructura a través de espacios y fronteras simbólicas. Se esperan diversos roles y comportamientos sociales por parte de esa actriz en determinados espacios sociales. Hay también lugares simbólicos asociados a esferas de poder, donde las actividades están limitadas y quizá el acceso sea denegado a la mayor parte de las personas, como son el hogar propio, y dentro de él, el dormitorio ${ }^{20}$. La población tiene su propio espacio personal en el que goza de un supuesto poder absoluto. Otros grupos sociales, y por qué no diferentes especies, tienen también su poder relativo.

Se observa un espacio donde domina el ser humano, que es la ciudad, de su propiedad. En ese espacio el ser humano tiene autoridad suprema frente a la naturaleza y los animales. Hay animales que habitan también ese territorio, pero están ahí porque asi se quiere (perros, gatos) o bien porque no se ha conseguido eliminarlos todavía (cucarachas, moscas, ratas). Una paloma está bien vista sobre una farola, y se permite su existencia. Pero no lo estaría un buitre, y se tomarían medidas para expulsarlo o bien exterminarlo. Por otra parte, parece natural y justo: "Éste es mi espacio, no te entrometas en él, así como yo no me entrometo en el tuyo". En el hogar se mataría sin dudar a una serpiente (no doméstica), pero no se le haría nada si se la encontrase en la naturaleza. Pero, si el territorio del ser humano es la ciudad (al menos en un principio) ¿dónde se encuentra el territorio del animal? En la naturaleza se contesta a esta pregunta. Pero ¿en qué naturaleza?, ¿en la naturaleza real o en la disneylandizada como no-lugar? La naturaleza como no-lugar sanciona la conquista del espacio animal, ya que el verdadero territorio animal está en un no-sitio, es decir, no existe. El santuario del animal es un no-lugar.

La conquista de un territorio pasa por varias fases. La primera es la de la personalización ${ }^{21}$. Se trata de la imposición de di- versas marcas o pequeñas transformaciones del espacio que anuncian el territorio como nuestro; como la orina en un árbol para los perros, o el alambre de espino en el bosque para los seres humanos. John LOCKE (1632-1705) introduce sin saberlo la cuestión cuando argumenta que en el estado de naturaleza el ser humano posee cosas únicamente cuando las transforma de algún modo a través de su esfuerzo. Karl MaRX (1818-1883) vuelve a esa misma idea. El objeto es introducir alguna marca en un territorio, y así transformado, como podría ser con una cerca de alambre de espino, convertir el territorio en humano. A partir de ese momento se puede decidir expulsar/exterminar todo lo que en él habita. Se pueden eliminar las "malas" hierbas, las serpientes, decidir que ciertas flores pueden quedarse, o que los jabalies son indeseables porque estropean el sembrado. El territorio experimenta una modificación lenta, lo que ayuda a ver el proceso como algo más natural, hasta el punto de que en algún momento no se recuerda ese espacio en su fase no colonizada. Hay varias formas de asegurar el control sobre un territorio. Irónicamente una de ellas es la contaminación ${ }^{22}$. Mediante la impurificación de un lugar se logra el monopolio sobre un territorio, sobre su acceso o uso. Esos procesos de personalización y transformación del territorio no afectan a la naturaleza, precisamente porque es un no-lugar.

La ciudad crece día a día, escapándose a sus barreras físicas. Los/las urbanitas aumentan en número, creando una naturaleza a su gusto en base a un reflejo idealizado de sus aspiraciones. La conquista del espacio natural se sanciona luego por el ecologismo, ocupado en la autocomplacencia de sus correlegionarios, y por la idea de esa naturaleza idealizada siempre virgen. El proceso se basa en un desconocimiento de la naturaleza. Se suele idealizar precisamente lo que se desconoce. Quizá ese desconocimiento proviene de la disociación temprana entre ser bumano y naturaleza, o entre ciencia y naturaleza que debate el viejo Aristóteles. Se produce así la negación de la propia animalidad del ser humano, y se percibe a lo natural como el otro", frente a lo racional y científico, personalizado por el ser humano.

Estos procesos sociales finiseculares parecen conducir a un mismo "escenario" (término que está de moda). A la izquierda se observa un paisaje dominado, mutilado, colmado de cercos y alambre de espino, lleno de especies animales políticamente correctas haciendo cola hacia el matadero. Animales salvajes esquivando su exterminio, árboles talados para construir chalets desde los cuales ver el bosque (a lo lejos) antes de ir a navegar por internet. A la derecha, en cambio, se puede ver una naturaleza frondosa en un eterno verano, donde Bambi corretea alegremente mientras charla con Bugs Bunny. Según las políticas verdes que se apliquen, una de esas dos naturalezas va a ser la que se disfrute en el cercano siglo XXI. 
- Universidad Pública de Navarra.

1 Agradezco especialmente las ideas de Juan M. Iranzo, de Jesús Oliva, el apoyo del Departamento de Sociología de la Universidad Pública de Navarra y a la University of Central England de Birmingham (Reino Unido), así como las excelentes sugerencias de William Claymore.

: Juan M. IRANzo, Ecologismo y religión civil: Ética y política en la modernidad avanzada., Politica y Sociedad 23 (1996), pp. 173-192.

Juan M. Iranzo, ibidem, pp. 175 y 187.

' Alfred SAUVY, Los mitos de nuestro tiempo (Barcelona: Labor, 1969).

" Marc AuGÉ, Los •no-lugares: Espacios del anonimato (Barcelona: Gedisa, 1992).

"Michael BeGon, John L. HaRPER, y Colin R. Townsend, Ecologia, individuo, población y comunidad (Barcelona: Omega, 1988).

' En inglés incluso se cambia el nombre del animal respecto de su carne: pig/pork, cow/veal.

${ }^{8}$ María Jesús Buxo y Jesús M. DE Miguel, eds., De la investigación audiovisual (Barcelona: Proyecto A, 1999).

$?$ El idioma ofrece un ejemplo adecuado. Cuando un animal (perro, gato) tiene nombre, se le puede calificar con el pronombre demostrativo éste, cuando no lo tiene, pasa a ser esto. Éste es Toby, esto es un perro. Los animales que están más en contacto con el ser humano (perros, gatos, caballos, canarios y otros seres humanos) que suelen tener nombre, son tabú para comer. La razón es que son seres morales. 1i. Véase la excelente recensión de Jesús M. DE MiGuEL, del libro de Robert E. LAMB, ed., Love Analyzed (Boulder, Colorado: Westwiev Press, 1997), en la Revista Española de Investigaciones Sociológicas 82 (1998), pp. 337-349.

"Sigmund Freud, La psicologia de las masas (Madrid: Alianza, 1984).

1: Juan M. IRAvzo, (1996), op. cit.

1. Javier ECHEVERRIA EZPONDA, Telépolis (Barcelona: Destino, 1994).

"Guy SORMAN, Los verdaderos pensadores de nuestro tiempo (Barcelona: Seix-Barral, 1991), pp. 26-33.

15 Jesús M. DE Miguel, Emilio J. CASTILLA, y Jordi CAïs, La sociedad transuersal (Barcelona: Fundación la Caixa, 1994), p. 166.

l" Javier ECHEverría EZPONDA (1994), op. cit.

1: Hugh Clout, Geografía nural (Barcelona: Oikós-Tau, 1976).

18 Benjamín García SANz, eNuevas claves para entender la recuperación de la sociedad rural, Papeles de Economia Española 61 (1994), pp. 204-218.

1) Ibidem.

" Erving Gofrmav, Relaciones en público: Microestudios de orden puiblico (Madrid: Alianza Editorial, 1979).

$\therefore$ Irwin ALTMAN, The Environment and Social Bebavior, (Belmont, Califomia: Brooks/Cole, 1975).

2 Erving Goffmav, (1979), op. cit. 